\title{
Adult attention deficit hyperactivity disorder: translating research into practice
}

\author{
A. N. Coogan • A. Dobrean • R. M. Donev • \\ L. Mateescu $\cdot$ U. Müller $\cdot$ J. Thome $\cdot$ \\ B. I. Voinescu
}

Received: 11 January 2012/ Accepted: 7 February 2012/Published online: 16 February 2012

(C) Springer-Verlag 2012

\begin{abstract}
Attention deficit hyperactivity disorder (ADHD) in adults is a prevalent, yet under-appreciated, underresearched and poorly understood condition. Given this, it is imperative that information and awareness regarding this condition are made more widespread, both amongst the general public and amongst healthcare professionals. Further, given our poor understanding of the aetiology of the condition, meaningful translational research that migrates into and better informs clinical practice must be a priority. In this brief review we highlight areas regarding the clinical diagnosis and management of ADHD in adults (guidelines, rating scales, pharmacotherapy, psychotherapy) as well as
\end{abstract}

A. N. Coogan, A. Dobrean, R. M. Donev, L. Mateescu, U. Müller, J. Thome, B. I. Voinescu contributed equally to this article.

A. N. Coogan

Department of Psychology, National University of Ireland

Maynooth, Maynooth, Leinster, Republic of Ireland

A. Dobrean · B. I. Voinescu ( $\square)$

Department of Clinical Psychology and Psychotherapy,

Babeş-Bolyai University, Cluj-Napoca, Romania

e-mail: bogdan.voinescu@ubbcluj.ro

R. M. Donev - J. Thome

Clinic and Policlinic of Psychiatry and Psychotherapy,

University of Rostock, Rostock, Germany

R. M. Donev · J. Thome

College of Medicine, Swansea University, Swansea, UK

L. Mateescu

Department of Child and Adolescent Psychiatry, Carol Davila

University of Medicine and Pharmacy, Bucharest, Romania

U. Müller

Department of Psychiatry, University of Cambridge,

Cambridge, UK areas of promising translational research (genetics, neuroimaging, sleep and circadian rhythms, animal models of ADHD). We address some of the challenges presented for both clinicians and healthcare providers and research scientists working to improve the lives of those adults with ADHD.

Keywords ADHD · Adult · Guidelines · Genetics · Sleep

\section{Introduction}

Attention deficit hyperactivity disorder (ADHD) is a widespread neurodevelopmental disorder, which is still considerably under-researched in adult patient populations (Asherson et al. 2010). The condition is characterised by concentration deficits, inner restlessness/hyperactivity, and impulsivity and is possibly associated with specific genetic and neurobiological alterations (Retz et al. 2008; Schneider et al. 2006). The symptomatology changes during lifetime and is, especially in adulthood, often associated with a plethora of comorbidities such as addiction, mood swings and personality accentuations (Kooij 2010). The persistence from childhood into adulthood is believed to be about $33 \%$, while the prevalence in the general adult population is around 5\% (Franke et al. 2011). However, there are several population subgroups with a significantly increased prevalence, for example, prison inmates or people suffering from alcoholism (Retz et al. 2004). ADHD-like symptoms were first described by Heinrich Hoffmann as early as 1864 (Thome and Jacobs 2004), although it took several decades until the behavioural phenomena were recognised as a medical condition (Taylor 2011). Today, several guidelines have been published which help to standardise and optimise the treatment of ADHD patients (Table 1). Also, the 
Table 1 ADHD guidelines with recommendations for adults (for details see Seixas et al. 2011)

\begin{tabular}{|c|c|c|c|}
\hline Guideline & Authors & Year & Country/continent \\
\hline DGPPN & Ebert, Krause, Roth-Sackenheim (eds) & 2003 & Germany \\
\hline EuNetHyDis & Dodwell et al. & 2006 & Europe \\
\hline Experts & Banaschewski et al. & 2006 & Europe \\
\hline BAP & Nutt et al. & 2007 & UK \\
\hline NICE & Taylor et al. & 2008, reviewed $2011^{a}$ & UK \\
\hline RACP & Forbes et al. & 2009 (draft) & Australia \\
\hline CADDRA, 3rd edition & Weiss and Vincent (eds) & 2011 & Canada \\
\hline
\end{tabular}

a National Institute for Health and Clinical Excellence (2011) Review of clinical guideline (CG72) — attention deficit hyperactivity disorder http://www.nice.org.uk/nicemedia/live/12061/57052/57052.pdf

empirical knowledge about the pathophysiology of the condition and consequently potential new preventive, diagnostic and therapeutic measures has increased substantially in recent years. Nevertheless, a better and faster translation of the accumulated scientific data into clinical practice is urgently needed.

\section{State of the art}

Diagnosis and assessment

Initially coined "minimal brain disorder", an ADHD concept in adults was developed as late as 1976 (Wood et al. 1976). Though nowadays the most widely used criteria are the ones proposed by the American Psychiatric Association in the Diagnostic and Statistical Manual of Mental Disorders (DSM-IV-TR), they have significant limitations, mainly arising from DSM-IV-TR criteria being derived from field trials in children. Specifically, the types of symptoms listed, the number of symptoms required, the age at onset and how impairment is measured are problematic (Barkley et al. 2007). The American Psychiatric Association has already been working on an updated set of criteria that is due to be published next year in DSM-5 (American Psychiatric Association 2010).

The disorder is diagnosed in adults who are currently experiencing symptoms and who can give a history of similar symptomatology in their childhood. Often retrospective, diagnosis is complex and difficult: symptoms vary in severity from individual to individual and may be found in people without the disorder; neither symptom report, neuropsychological testing, nor objective tests (blood, imaging) are specific to ADHD. Therefore, a number of interviews and scales were developed to help diagnosis and assessment. Several interviews, specifically designed for ADHD, have been published, and each has its own advantages and limitations (Rosler et al. 2006); further, structured clinical interviews such as the Structured
Clinical Interview for DSM-IV (SCID) or the shorter and time-efficient Mini-international Neuropsychiatric Interview (MINI 6.0 Plus) (Sheehan et al. 1998) are useful in systematically assessing other conditions.

Being cost-effective, aiding diagnosis and quickly gathering a large amount of data, rating scales are widely used by both clinicians and researchers, in observer, self-report or informant forms. While some only list the classical triad of DSM criteria, others also gather other psychopathological information and symptomatology considered to be of clinical significance (for reviews and comparisons see Rodriguez and Simon-Dack 2011; Rosler et al. 2010; Taylor et al. 2011; Van Voorhees et al. 2011). Although there is no gold-standard or ideal rating scale, the Adult ADHD Self Report Scale (ASRS) screener should be mentioned for its brevity and availability in many languages (Kessler et al. 2007). Despite the large number of available instruments, particularly written American English, there is not a single one available in all the European languages. Some European researchers developed their own instruments (Kooij 2010; Young and Gudjonsson 2005), but we believe that research should focus not on developing new ones, but on translating and validating the existing ones, paying attention on possible differences in social-cultural background, as well as on linguistic problems (Rogers et al. 2009).

\section{Pharmacotherapy}

The pharmacological treatment for ADHD in adults with stimulants and non-stimulants is well established. D-Amphetamine was introduced in 1944 and methylphenidate in 1954; the two stimulants are some of the oldest and best known psychopharmacological agents still widely in clinical use (Iversen 2008). NICE (Taylor and al. 2008) recommends drug treatment as the first-line treatment "unless the person would prefer a psychological approach". This influential ADHD guideline prioritises methylphenidate, which "should normally be tried first". 
"Drug treatment for adults with ADHD should always form part of a comprehensive treatment programme that addresses psychological, behavioural and occupational needs". Other guidelines recommend amphetamine, mixed amphetamine salts, lisdexamphetamine and atomoxetine as first-line treatment for adults with ADHD (Seixas et al. 2011).

Guideline recommendations are based on accumulating positive evidence from randomised placebo-controlled clinical trials (RCTs) of pharmacological treatments in adults with ADHD. The most recent meta-analysis of 17 methylphenidate studies reports a medium effect size of 0.48 (Castells et al. 2011) another recent meta-analysis reports numbers needed to treat (NNT) around 3 for psychostimulants and around 5 for atomoxetine (Faraone and Glatt 2010), these are some of the lowest NNTs reported across all disciplines in medicine (Leucht et al. 2011), which means that medication for ADHD in adults can be considered as one of the most effective treatments, at least in the short term. Symptom remission curves of RCTs with psychostimulants show relatively rapid onset of action as compared to studies with atomoxetine (Adler et al. 2009). Controlled studies with duration up to 6 months and open studies up to 4 years (Adler et al. 2008) have shown efficacy and relatively good tolerability of ADHD medication in adults in the longer term.

The most common side effects are anxiety/depression, sleeping problems, reduced appetite and increased blood pressure. Careful dose titration and monitoring of side effects are recommended (Taylor et al. 2008). A recent study of more than 150,000 treatment episodes compared to nearly 300,000 control episodes showed no increased risk of serious cardiovascular events in adults treated with methylphenidate, amphetamine or atomoxetine (Habel et al. 2011). There is generally less evidence from RCTs the treatment for ADHD in patients with comorbid psychiatric and general medical conditions. Guidelines do not endorse prescribing of ADHD medication for people without a diagnosis of ADHD for the purpose of cognitive enhancement (Larriviere et al. 2009).

The big challenge for evidence-based medicine is the translation of research findings into clinical practice. There are detailed evidence- and consensus-based recommendations for the pharmacological treatment for ADHD in adults (Kooij et al. 2010; Seixas et al. 2011); however, in most European countries, the number of specialist clinics for adults with ADHD and clinical expertise are growing only slowly. Austerity programmes for public health systems make it especially difficult to implement guideline recommendations in daily practice and for the neediest patients. Nevertheless, initiatives like the UK Adult ADHD Network (http://www.ukaan.org.uk) and the European Network Adult ADHD (Kooij et al. 2010) organise training, coordinate research and support the development of services for adults with ADHD.

The cost of medication varies between countries, but is not much higher than for the pharmacological treatment for other chronic mental health conditions. Short-acting stimulants are generally cheaper than extended release preparations or atomoxetine. Most ADHD drugs are "off label" for adults, and psychostimulants are controlled drugs which make prescribing complicated in daily practice. Strattera and Concerta have carry on licenses in some countries, and Medikinet adult is licensed in Germany (Retz et al. 2011).

\section{Psychotherapy}

Psychological treatments may play a critical role in the management of adults with ADHD, provided that sufficient motivation is present to allow for the acquisition of new skills (Weiss and Vincent 2011). They are not designed as sole treatment for adult ADHD, but to help the patients to adjust to a lifelong debilitating disorder and to address the consequences of the comorbid disorders.

Cognitive and behavioural psychotherapies (CBTs) are the most widely researched psychological interventions for the treatment of adult ADHD (Ramsay and Rostain 2007). Mahoney and Arnkoff (1978) categorised CBTs in three main classes: cognitive restructuring, coping skills therapies and problem-solving therapies. All of these approaches have been taken into consideration in the last years as possible interventions for adult $\mathrm{ADHD}$ and have been incorporated in individual cognitive-behavioural therapy (Rostain and Ramsay 2006; Safren et al. 2005, 2010) and in group interventions (Hesslinger et al. 2002; Philipsen et al. 2010; Solanto et al. 2008; Virta et al. 2008). The results are promising, both in the improvement of core ADHD symptoms (as measured with self-ratings and/or independent evaluations) and in comorbid conditions, such as anxiety and depression (Emilsson et al. 2011; Safren 2006). Further studies need to address more clearly the efficacy of the CBT in combination with medication, both at the end of the treatment and at follow-up.

Except CBTs, there are several other forms of psychological interventions used in the treatment for adult ADHD such as psychoeducation (Murphy 2005; Weiss and Weiss 2004), family therapy (Barkley 2006; Murphy 2005), vocational counselling and coaching (Favorite 1995; Kubik 2010). They may be used in the larger frame of CBTs or in combination with pharmacological treatment.

The objectives of a treatment programme for adult ADHD should address core symptoms of ADHD, comorbid disorders, psychosocial impairment, psychosocial functioning and self-confidence, family relationship/functioning, interpersonal (broader than family) functioning, professional or academic functioning, cognitive deficits, 
driving performance, risk of substance misuse or abuse (Solanto 2011). Clinicians ought to recognise and approach ADHD as a chronic condition in which patients generally require special long-term mental health care. The evaluation and the treatment schedule should take into consideration the developmental level of the adult condition, ADHD characteristics in the adult and the demands and responsibilities of the adult life. Both during the evaluation and treatment, the clinician has to be aware of the current patients' background, their history ("the child inside the adult and his family history"), their future and the future of their children ("the parent inside the adult"). Significant others (partner, parents, siblings, close friends, etc.) should be involved as members in the treatment team. The stigma of a mental health problem should be taken into consideration and can even represent one of the intervention targets.

\section{Translational research}

\section{Dopaminergic neuroimaging}

The rapid progress of neuroimaging in psychiatric research is driven by methodological progress, increasing the capacity of clinical neuroimaging laboratories and fascinating discoveries. Neuroimaging of patients with ADHD across the lifespan is booming and has produced the first robust findings (Schneider et al. 2006). Structural magnetic resonance imaging (MRI) findings in ADHD have been meta-analysed with relatively consistent findings that may be of diagnostic relevance in the future (Frodl and Skokaukas 2011; Nakao et al. 2011). The rest of this selective mini review of latest research findings summarises PET studies of the dopamine system and functional MRI (fMRI) studies investigating the effects of ADHD medication on brain function.

The best set of structural MRI data comes from the National Institute of Mental Health (NIMH) cohort of more than 400 ADHD patients and healthy controls followed up with regular clinical ratings and structural MRI into adulthood (for up to 33 years). Adults with a childhood diagnosis of ADHD showed decreased total cerebral volume, reduced global cortical thickness and reduced volumes of subcortical structures. Volume reductions were more pronounced in patients with persisting symptoms, whereas symptom amelioration and diagnostic remission were accompanied by compensatory maturation of frontalthalamic-cerebellar circuits (Proal et al. 2011). Cortical thickness in the frontal cortex peaks around the age of 7-8 in normal children, but later in children with ADHD (maturational delay). In an analysis of a subsample of 9- to 20-year-old patients, who were scanned twice, treatment with psychostimulants was not associated with slowing of overall growth of the cortical mantle, and this was interpreted as "a notable finding given reports of possible psychostimulant-related slowing of height and weight gain" (Shaw et al. 2009).

Most other structural MRI studies in ADHD are crosssectional case-control studies and limited by relatively small sample sizes. Two recent meta-analyses of voxelbased morphometry (VBM) and region of interest (ROI) studies find volume reductions in the right globus pallidus and putamen in ADHD (Frodl and Skokaukas 2011; Nakao et al. 2011). Meta-regression for mean sample age and percentage of medicated patients show that most of the structural deficits in children grow out over time and that there are fewer structural abnormalities in studies with mostly medicated patients. This seems to indicate that long-term medication can normalise structural deficits in brains of patients with ADHD.

In the last decade, a series of PET (and SPECT) studies investigating the dopaminergic system in ADHD have been published (Table 2). Most studies have relatively small samples sizes, and some findings are controversial. [18F]Dopa availability in the striatum of adults and children with ADHD was consistently reduced, indicating a problem in dopamine synthesis. Deficits in the presynaptic dopamine system are also indicated by a PET study that showed blunted striatal dopamine release after intravenous methylphenidate in adults with ADHD as measured by [11C]raclopride displacement (Volkow et al. 2007). This finding could, however, not be replicated after pharmacological treatment (Volkow et al. 2012) and in a study with $[18 \mathrm{~F}]$ fallypride after oral methylphenidate (del Campo et al. 2011). One of the most ambitious PET studies ever performed in a psychiatric population was carried out by Volkow et al. (2009, 2011). Never-medicated adult ADHD patients $(n=55)$ from New York, California and North Carolina and healthy controls $(n=44)$ were scanned with [11C]cocaine and [11C]raclopride at the Brookhaven PET laboratory between 2001 and 2009. Patients showed significantly lower availability of D2/D3 dopamine receptors and dopamine transporter (PET); there was, however, a considerable overlap of individual binding potential ratios between patients and healthy controls. The severity of ADHD symptoms and motivational deficits in patients (and controls) correlated with striatal dopamine receptor density (Volkow et al. 2009, 2011). Previous PET and SPECT studies with smaller sample sizes reported increased, unchanged or decreased availability of the dopamine transporter (DAT) in adults with ADHD as compared to controls; such heterogeneity can be explained by the percentage of never-medicated patients (Mehta and Krause 2011). 
Table 2 PET/SPECT studies of the dopamine system in ADHD with publication year and authors (see del Campo et al. 2011 for detailed references)

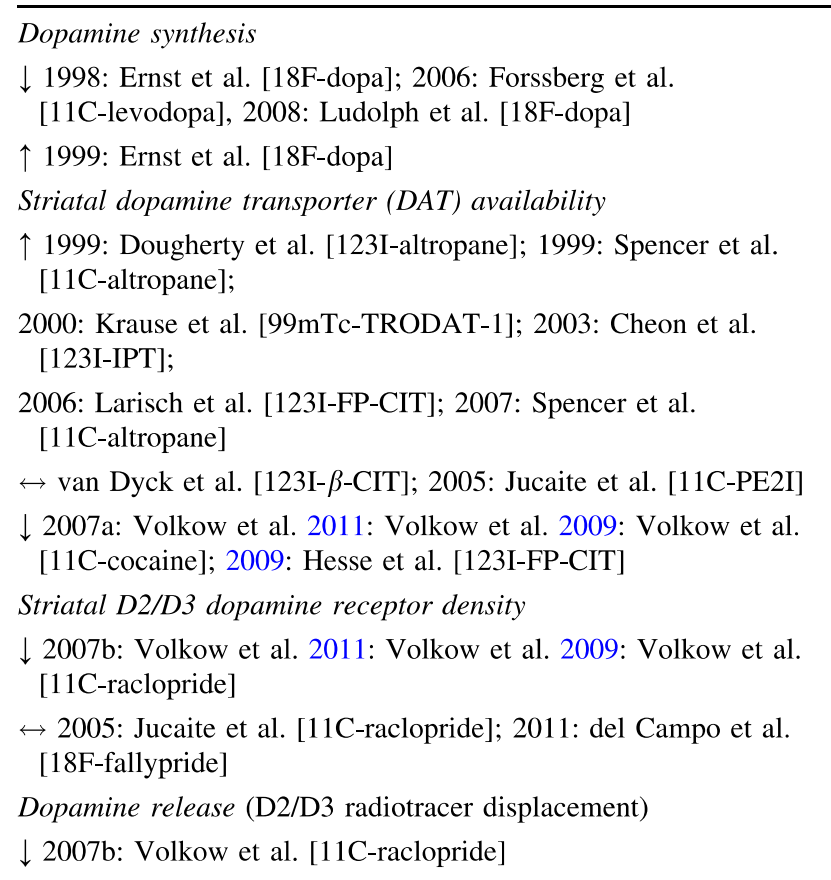

$\uparrow$, increased; $\downarrow$, reduced; $\leftrightarrow$, unchanged regional availability (as compared to healthy controls); [ligand]

Another interesting approach to investigate neurotransmitter abnormalities and effects of ADHD medication on brain activity is pharmacological fMRI. In a series of experiment the group in Cambridge could demonstrate that stop signal reaction time, a cognitive correlate of motor inhibition and impulsivity, is increased in patients with ADHD and normalised by simple doses of ADHD medication (Chamberlain et al. 2011). Stopping-related brain activity in the inferior prefrontal cortex was increased after a single dose of atomoxetine, and this increase correlated positively with plasma levels of atomoxetine measured immediately before and after fMRI scanning (Chamberlain et al. 2009). Pharmacological fMRI studies in patients with ADHD are in preparation, and standardised structural and functional neuroimaging parameter have a potential as novel endpoints in clinical trials (Valenzuela et al. 2011).

\section{Neurotransmitter genetics}

It is not known exactly what causes $\mathrm{ADHD}$, but vast number of studies suggest the causes could be largely genetic, combined with some other factors. For example, in identical twins, there is a $72-83 \%$ probability that both will have ADHD. In non-identical same-sex twins, the probability is $21-45 \%$ (Franke et al. 2011). Parents, siblings and children of people with ADHD may be up to five times more likely to have the disorder than people who are not related to someone with ADHD. Initially, it was thought there could be just one or a few genes that cause development of ADHD. However, the high population frequency of the disorder, the heterogeneity of studies with twins and association analyses in families have suggested that ADHD is probably caused by several genes, each of which makes a major or a minor contribution. Pharmacologic, neuroimaging studies and different animal models suggested that an imbalance of dopaminergic, serotonergic, and noradrenergic neurotransmission is likely to result in ADHD. Therefore, monoamine genes were strong a priori candidates, and the majority of studies have been focused on these genes.

The two major methods used to identify genes associated with ADHD are genetic linkage analysis and allelic association studies. The genetic linkage analysis is a statistical method that is used to associate functionality of genes with their location on chromosomes. The main idea of the method is that neighbouring genes on the chromosome have a tendency to stick together when passed on to offsprings. Therefore, if some disease is often passed to offsprings along with specific marker genes, then it can be concluded that the gene(s) which are responsible for the disease are located close on the chromosome to these markers. In contrast, while the genetic linkage analysis studies the inheritance of genes in families, allelic association studies are based on the phenomenon of linkage disequilibrium in unrelated cases of ADHD and compares frequencies of neutral SNP in cases of ADHD to those in control subjects. This allows pinning down aetiological genes for ADHD from a large group of genes in a region showing linkage with ADHD derived from family data. Combining these two methods with neuroimaging, pharmacologic data and animal model studies identified around thirty neurodevelopmental genes that were implicated in ADHD aetiology to some extent-DAT1, DRD4, DRD5, TACR1, HTR1B, DBH, ADRA1A, ADRA2A, TPH1, TPH2, HTR2A, SLC6A2, SLC5A4, SNAP25, CHRNA4, COMT, MAOA, etc. (reviewed in Smith et al. 2009; Langley et al. 2009; Coghill and Banaschewski 2009).

Although many genes have been found to be associated with ADHD, meta-analyses failed to establish significance in many of these associations. Some of the genes associated with ADHD due to pharmacological and neuroimaging studies have not been determined as risk genes by the genetic methods. In addition, the functional role of polymorphisms significantly associated with the disorder is largely unknown. This justifies further studies to determine the effect of polymorphisms on gene function and development of ADHD symptoms in order to develop treatments targeting appropriate genes. Furthermore, a number of 
genes and signalling pathways which are likely to be of a great importance for the brain development and development of ADHD symptoms, respectively, have not been studied at all (reviewed in Donev and Thome 2010). For example, we have unpublished data confirming the association of certain polymorphisms in complement system with both child and adult ADHD. The role of complement in brain development has been recently established (Boulanger 2009; Veerhuis et al. 2011). Therefore, further complex molecular and functional analyses are urgently needed to identify novel targets for treatments of ADHD, which are likely to be more efficient and with limited adverse effects.

\section{Sleep and circadian rhythmicity}

Like many other psychiatric conditions, ADHD is associated with poor sleep. Between 25 and $50 \%$ of children and adolescents with ADHD have impaired sleep quality, whilst it has been reported that over $50 \%$ of adults with ADHD present with sleep problems (Yoon et al. 2011). Indeed, $27 \%$ of adults with ADHD fulfil the DSM-IV diagnostic criteria for insomnia (Schredl et al. 2007). The reason for such high levels of sleep disturbances in ADHD is not clear, although it is interesting to note that primary sleep disorders can produce symptoms such as difficulty sustaining attention and impulsivity to the extent that the diagnostic criteria for ADHD may be fulfilled (Wulff et al. 2010). For example, Oosterloo et al. (2006) reported that $18 \%$ of patients with excessive daytime sleepiness can be diagnosed as having $\mathrm{ADHD}$, whilst conversely $37 \%$ of those with an ADHD diagnosis display excessive daytime sleepiness. Childhood ADHD is best studied from the sleep perspective and is associated with increased sleep latency, REM sleep latency and daytime sleepiness (reviewed in Yoon et al. 2011). There are also elevated levels of primary sleep disorders such as restless leg syndrome, periodic limb movement disorder and sleep-disordered breathing associated with child and adolescent ADHD. Recently, novel potential causes for sleep disturbance in ADHD have been highlighted. One intriguing possibility is that eczema, which is found to occur more commonly in children with ADHD and disturbed sleep, may be a precipitating factor in impaired sleep patterns in ADHD and contribute significantly to the risk of developing ADHD (Romanos et al. 2011).

One physiological system that may be involved in the aetiology of sleep disturbances in ADHD is the circadian timing system, an intrinsic near 24-h timekeeper that in the classical two process model of sleep interacts with the sleep homeostat to determine the organisation of the sleep/ wake cycle (Borbely 1982). Since ADHD in children is associated with late bedtimes and difficulty falling asleep (chronic sleep onset insomnia), Van der Heijden et al. (2005) examined this link to the dim-light melatonin onset (DLMO), a marker of the phase of the circadian clock, and found that chronic sleep onset insomnia in ADHD is associated with a delayed DLMO, indicating that a disturbance of the circadian timing system may be an important factor in the sleep problems associated with ADHD. Following on from this, a small trial using melatonin treatment to correct the circadian misalignment reported significant benefit regarding sleeping, behavioural and cognitive problems over a nearly 3-year follow-up period (Hoebert et al. 2009). In adults, Boonstra et al. (2007) report that ADHD is associated with increased sleep onset latency and decreased sleep efficiency as well as lower subjective sleep quality ratings and that methylphenidate has the effects of leading to later bedtimes and shorter sleep times, but increased sleep efficiency. In a further study, Van Veen et al. (2010) reported that the prevalence of chronic sleep onset insomnia in adult ADHD was of the order of $75 \%$ and that this in turn was linked to a delay in the DLMO and the general circadian activity profile as determined by actigraphy.

Given the accumulating evidence that circadian rhythms are compromised in ADHD, it is of interest to enquire as to the mechanisms through which this may be occurring. Kissling et al. (2008) have reported that a single nucleotide polymorphism in $C L O C K$, a gene central to the molecular operation of the circadian clock, is associated with higher ADHD scores in adults, a finding replicated by $\mathrm{Xu}$ et al. (2010). Further to this, Baird et al. (2011) examined whether the rhythmic expression of clock genes, the molecular mechanism by which circadian time is encoded, was altered in adult ADHD. This study reported that rhythmic expression of two such genes, BMAL1 and PER2, over twenty-four hours was ablated in the adult ADHD group. Further, these authors reported that cortisol circadian rhythms are significantly phase-delayed compared to controls, and that motor patterns determined with actigraphy also show evidence for altered circadian entrainment to environmental time cues. These circadian alterations occurred alongside changes in objectively determined sleep parameters (Baird et al. 2011). Finally, these authors also demonstrate inverse correlations between measures of circadian rhythm robustness and clinical ADHD ratings, suggesting that more severe ADHD scores are associated with weaker measures of circadian rhythms. These findings raise the possibility that chronotherapeutic approaches designed to bolster weakened circadian rhythms may be of benefit in adult ADHD. Further issues that require addressing include the extent to which comorbid disorders contribute to the circadian and sleep disruption in ADHD and how stimulant and non-stimulant medication may also contribute to such effects (O'Keeffe et al. 2011). 
Animal models

In many areas of translational neuropsychiatric and psychopharmacological research, the use of animal models has contributed significantly to the understanding of the underlying pathophysiological mechanisms and the formulation of new pharmacotherapeutic strategies. Animal models offer the benefit of applying modern transgenic technologies to understanding the molecular mechanism underpinning serious and common psychiatric disorders, as well as allowing for the application of invasive neuroscientific approaches (e.g. in vivo microdialysis or electrophysiology) that are not possible in patient studies.

In attempting to model ADHD, as in models for other conditions, animal models must be tested against three criteria for their validity: (1) face validity assesses the symptomatic similarities between the animal model and the clinical condition; (2) construct validity assesses the pathophysiological similarities between the animal model and the clinical condition; and (3) predictive validity assesses how useful the model is in predicting therapeutic responses in patient populations (Russell 2011; Sontag et al. 2010). These criteria present a particular challenge in modelling a condition such as ADHD in which the aetiology is so poorly defined, and therefore, any animal model of the condition is bound to have limited construct validity. However, this issue also highlights the potential usefulness for animal models of ADHD to increase pathophysiological insight into the clinical condition. Further to assess the validity of the animal model itself, one must assess the behavioural tests applied to the model and query their salience for mimicking the clinical picture-for example, since hyperactivity in ADHD is strongly associated with familiar environments with novel environments inducing hypoactivity, measuring open field activity in a novel arena in an animal model as a correlate of hyperactivity in ADHD is not likely to reveal appropriate insight.

The best characterised animal model for ADHD is the spontaneously hypertensive rat (SHR), an inbred rat selected in the 1960s for its hypertension but which also exhibits hyperactivity, leading to its investigation in an ADHD context (Sagvolden and Johansen 2011). Much insight into this model has been gleaned using operant conditioning experiments with fixed intervals/extinction paradigms which display increased responding (e.g. lever pressing) during the extinction phase when no reward is available in SHRs, analogous to the situation found in children with ADHD and suggests that the extinction curve in SHRs and ADHD may be steeper than in controls (Sagvolden 2000; Sagvolden et al. 2005). Tests requiring sustained attention also illustrate deficits in SHRs similar to those observed in ADHD (Sagvolden 2000). SHRs also demonstrate high levels of temporal discounting, preferring smaller but immediate rewards over larger but delayed ones, again similar to the situation observed in ADHD (Fox et al. 2008). SHRs express hyperactivity in familiar environments, and this hyperactivity has been reported to be calmed by treatment with amphetamine (Sagvolden 2011) but not methylphenidate (van den Bergh et al. 2006). From a neurochemical perspective, SHRs showed diminished levels of both the dopamine and monamine transporters, as well as altered dopamine release (Simchon et al. 2010) in broad agreement with the implication of dopaminergic function in the pathophysiology of ADHD. Further, the SHR is found to carry polymorphisms in the dopaminetransported gene (DAT), similar to the associations found in ADHD (Mill et al. 2005). The use of the SHR in modelling $\mathrm{ADHD}$ is somewhat limited by the presence of hypertension, which develops in early adulthood in these animals (a particularly important point when considering modelling adult ADHD), and the use of the control strain, the Wistar Kyoto rat, which itself is found to be hypoactive and shows an increase in depressive-like behaviours. Overall, the SHR is the best characterised animal model for ADHD, displaying good face validity and reasonable construct and predictive validity.

Other models of ADHD include the DAT-knockout/ knock-down/upregulated mouse, in which the dopaminergic system is manipulated via genetic alterations in the expression of the dopamine transporter (Gainetdinov 2010), the thyroid hormone receptor beta(1) knockout mouse in which a gene carrying a human mutation conferring resistance to thyroid hormone is expressed in the mouse (Siesser et al. 2006), and recently developed novel models including the membrane receptor guanyl cyclase $\mathrm{C}$ knockout mouse (Gong et al. 2011) and the GIT-1 knockout mouse (Won et al. 2011). All of these models show some validity, but the characterisation of these animals across the behavioural spectrum, and the replication of behavioural findings across different research groups is not presently sufficient, and further work is needed on these models. Future directions of research may include concentration on single symptomatic phenotypes (endophenotypes) rather than attempting to recapitulate the whole picture of a clinical complex and heterogeneous condition such as ADHD. However, it seems reasonable to presume that with sufficient care and caution taken, animal models still have important roles to play in translational ADHD research.

\section{Discussion and conclusion}

Despite its relatively high prevalence and its impact on quality of life, visibility of $\mathrm{ADHD}$ as a genuine adult 
condition remains low amongst the public and physicians. Much effort is needed to address this, particularly in countries such as Romania in which there is little to none specialist provision for adult ADHD. In aiding diagnosis and management of adult ADHD, there are a number of international guidelines available and a number of wellvalidated rating scales. Particularly for the use of diagnostic scales and interviews, effort should be directed into translating the available scales and validating these translations, rather than "re-inventing the wheel" and developing new scales that do much the same job. In terms of pharmacotherapy, psychostimulant treatment remains the gold-standard, with a significant played also by the non-stimulant atomoxetine. There are cost implications for the use of atomoxetine and long-release formulations of methylphenidate that may inhibit their use in different national health systems, a matter further complicated by the fact that in many national systems, these drugs are not licensed for adult use. There is also a significant role for psychotherapeutic approaches in the management of adult ADHD and accumulating evidence of the effective combination of both pharmacotherapy and psychotherapy.

Translation research approaches are yielding results that are improving our understanding of adult ADHD. The genetics of adult ADHD remain somewhat problematical (not something that is unique in psychiatric genetics), given that historically most studies to date are gene association studies focussing on "traditional" neurotransmitter systems and have lacked sufficient statistical power to provide clinically pertinent insight. Large genome-wide association studies are hoped to identify both common and rare allelic variants associated with adult ADHD and identify new cellular targets and processes in understanding the aetiology of the condition. The combination of genetics and neuroimaging is also likely to provide considerable insight into the pathophysiological origins of ADHD-like symptoms (e.g. impulsiveness and inattention). To date, neuroimaging approaches, along with work in animal models of ADHD, have been invaluable in shedding light on the altered brain function in ADHD, and although this information has not yet translated fulsomely into shaping clinical practice, the incorporation of neuroimaging endpoints in clinical trials surely represents a move in the right direction. Research concerning "non-core" symptoms of ADHD, such as sleep and circadian rhythm disturbances, also raises the possibilities of trialling novel treatment strategies in adult ADHD.

Acknowledgments This review is based on the results of an exploratory workshop that took place on 17-19 December 2011 at Babeş-Bolyai University, Cluj-Napoca, Romania, and was financially supported by CNCS-UEFISCDI, project number PNII-IDEI/WE2011-056.

\section{References}

Adler LA, Spencer TJ, Williams DW, Moore RJ, Michelson D (2008) Long-term, open-label safety and efficacy of atomoxetine in adults with ADHD: final report of a 4-year study. J Atten Disord 12(3):248-253. doi: 10.1177/1087054708316250

Adler LA, Liebowitz M, Kronenberger W, Qiao M, Rubin R, Hollandbeck M, Deldar A, Schuh K, Durell T (2009) Atomoxetine treatment in adults with attention-deficit/hyperactivity disorder and comorbid social anxiety disorder. Depress Anxiety 26(3):212-221. doi:10.1002/da.20549

American Psychiatric Association (2010) DSM-5: options being considered for ADHD. American Psychiatric Association. http:// www.dsm5.org/Proposed\%20Revision\%20Attachments/APA\%20 Options\%20for\%20ADHD.pdf. Accessed January 232012

Asherson P, Adamou M, Bolea B, Müller U, Morua SD, Pitts M, Thome J, Young S (2010) Is ADHD a valid diagnosis in adults? Yes. Br Med J 340:736-737. doi:10.1136/bmj.c549

Baird AL, Coogan AN, Siddiqui A, Donev RM, Thome J (2011) Adult attention-deficit hyperactivity disorder is associated with alterations in circadian rhythms at the behavioural, endocrine and molecular levels. Mol Psychiatr. doi:10.1038/mp.2011.149

Banaschewski T, Coghill D, Santosh P, Zuddas A, Asherson P, Buitelaar J, Danckaerts M, Döpfner M, Faraone S, Rothenberger A, Sergeant J, Steinhausen H-C, Sonuga-Barke E, Taylor E (2006) Long-acting medications for the hyperkinetic disorders. Eur Child Adoles Psychiatr 15(8):476-495. doi:10.1007/s00787006-0549-0

Barkley RA (2006) Attention-deficit hyperactivity disorder: a handbook for diagnosis and treatment, 3rd edn. Guilford Press, New York

Barkley RA, Murphy KR, Fischer M (2007) ADHD in adults: what the science says. Guilford Press, New York

Boonstra AM, Kooij JJ, Oosterlaan J, Sergeant JA, Buitelaar JK, Van Someren EJ (2007) Hyperactive night and day? Actigraphy studies in adult ADHD: a baseline comparison and the effect of methylphenidate. Sleep 30(4):433-442

Borbely AA (1982) A two process model of sleep regulation. Hum Neurobiol 1(3):195-204

Boulanger LM (2009) Immune proteins in brain development and synaptic plasticity. Neuron 64(1):93-109. doi:10.1016/j.neuron. 2009.09.001

Castells X, Ramos-Quiroga JA, Rigau D, Bosch R, Nogueira M, Vidal X, Casas M (2011) Efficacy of methylphenidate for adults with attention-deficit hyperactivity disorder: a meta-regression analysis. CNS Drugs 25(2):157-169. doi:10.2165/11539440000000000-00000

Chamberlain SR, Hampshire A, Müller U, Rubia K, del Campo N, Craig K, Regenthal R, Suckling J, Raoiser J, Grant JE, Bullmore ET, Robbins TW, Sahakian BJ (2009) Atomoxetine modulates right inferior frontal activation during inhibitory control: a pharmacological fMRT study. Biol Psychiatr 65:550-555. doi: 10.1016/j.biopsych.2008.10.014

Chamberlain SR, Robbins TW, Winder-Rhodes S, Müller U, Sahakian BJ, Blackwell AD, Barnett JH (2011) Translational approaches to fronto-striatal dysfunction in attention-deficit hyperactivity disorder using CANTAB. Biol Psychiatr 69: 1192-1203. doi:10.1016/j.biopsych.2010.08.019

Coghill D, Banaschewski T (2009) The genetics of attention-deficit/ hyperactivity disorder. Expert Rev Neurother 9(10):1547-1565. doi: $10.1586 /$ ern.09.78

del Campo N, Chamberlain SR, Sahakian BJ, Robbins TW (2011) The roles of dopamine and noradrenaline in the pathophysiology and treatment of attention-deficit/hyperactivity disorder. Biol Psychiatr 69:e145-e157. doi:10.1016/j.biopsych.2011.02.036 
Donev R, Thome J (2010) Inflammation: good or bad for ADHD? ADHD Atten Def Hyp Disord 2:257-266. doi:10.1007/s12402010-0038-7

Emilsson B, Gudjonsson G, Sigurdsson JF, Baldursson G, Einarsson E, Olafsdottir H, Young S (2011) Cognitive behaviour therapy in medication-treated adults with ADHD and persistent symptoms: a randomized controlled trial. BMC Psychiatr 11:116. doi: 10.1186/1471-244X-11-116

Faraone SV, Glatt SJ (2010) A comparison of the efficacy of medications for adults attention-deficit/hyperactivity disorder using meta-analysis of effect sizes. J Clin Psychiatr 71:754-763. doi:10.4088/JCP.08m04902pur

Favorite B (1995) Coaching for adults with ADHD: the missing link between the desire for change and achievement of success. ADHD Report 3:11-12

Fox AT, Hand DJ, Reilly MP (2008) Impulsive choice in a rodent model of attention-deficit/hyperactivity disorder. Behav Brain Res 187(1):146-152

Franke B, Faraone SV, Asherson P, Buitelaar J, Bau CH, RamosQuiroga JA, Mick E, Grevet EH, Johansson S, Haavik J, Lesch KP, Cormand B, Reif A (2011) The genetics of attention deficit/ hyperactivity disorder in adults, a review. Mol Psychiatr. doi: 10.1038/mp.2011.138

Frodl T, Skokaukas N (2011) Meta-analysis of structural MRI studies in children and adults with attention deficit hyperactivity disorder indicates treatment effects. Acta Psychiatr Scand [Epub ahead of print]

Gainetdinov RR (2010) Strengths and limitations of genetic models of ADHD. Atten Defic Hyperact Disord 2(1):21-30. doi:10.1007/ s12402-010-0021-3

Gong R, Ding C, Hu J, Lu Y, Liu F, Mann E, Xu F, Cohen MB, Luo M (2011) Role for the membrane receptor guanylyl cyclase-C in attention deficiency and hyperactive behavior. Science 333(6049): 1642-1646

Habel LA, Cooper WO, Sox CM, Chan KA, Fireman BH, Arbogast PG, Cheetham TC, Quinn VP, Dublin S, Boudreau DM, Andrade SE, Pawloski PA, Raebel MA, Smith DH, Achacoso N, Uratsu C, Go AS, Sidney S, Nguyen-Huynh MN, Ray WA, Selby JV (2011) ADHD medications and risk of serious cardiovascular events in young and middle-aged adults. JAMA 306:2673-2683. doi:10.1001/jama.2011.1830

Hesslinger B, Tebartz van Elst L, Nyberg E, Dykiere P, Richter H, Berner M, Ebert D (2002) Psychotherapy of attention deficit hyper-activity disorder in adults-a pilot study using a structured skills training program. Eur Arch Psychiatr Clin Neurosci 252(4):177-184

Hoebert M, van der Heijden KB, van Geijlswijk IM, Smits MG (2009) Long-term follow-up of melatonin treatment in children with ADHD and chronic sleep onset insomnia. J Pineal Res 47(1):1-7. doi:10.1111/j.1600-079X.2009.00681.x

Iversen L (2008) Speed, Ecstacy, Ritalin: the science of amphetamines. OUP, Oxford

Kessler RC, Adler LA, Gruber MJ, Sarawate CA, Spencer T, Van Brunt DL (2007) Validity of the World Health Organization Adult ADHD self-report scale (ASRS) screener in a representative sample of health plan members. Int J Methods Psychiatr Res 16(2):52-65. doi:10.1002/mpr.208

Kissling C, Retz W, Wiemann S, Coogan AN, Clement RM, Hunnerkopf R, Conner AC, Freitag CM, Rosler M, Thome J (2008) A polymorphism at the $3^{\prime}$-untranslated region of the CLOCK gene is associated with adult attention-deficit hyperactivity disorder. Am J Med Genet B Neuropsychiatr Genet 147(3):333-338. doi:10.1002/ajmg.b.30602

Kooij SJ (2010) Adult ADHD. Diagnostic assessment and treatment. Pearson Assessment and Information BV, Amsterdam
Kooij SJ, Bejerot S, Blackwell A, Caci H, Casas-Brugué M, Carpentier PJ, Edvinsson D, Fayyad J, Foeken K, Fitzgerald M, Gaillac V, Ginsberg Y, Henry C, Krause J, Lensing MB, Manor I, Niederhofer H, Nunes-Filipe C, Ohlmeier MD, Oswald P, Pallanti S, Pehlivanidis A, Ramos-Quiroga JA, Rastam M, Ryffel-Rawak D, Stes S, Asherson P (2010) European consensus statement on diagnosis and treatment of adult ADHD: the European network adult ADHD. BMC Psychiatr 10:67. doi: $10.1186 / 1471-244 X-10-67$

Kubik JA (2010) Efficacy of ADHD coaching for adults with ADHD. J Atten Disord 13(5):442-453. doi:10.1177/1087054708329960

Langley K, Fowler TA, Grady DL, Moyzis RK, Holmans PA, van den Bree MB, Owen MJ, O'Donovan MC, Thapar A (2009) Molecular genetic contribution to the developmental course of attention-deficit hyperactivity disorder. Eur Child Adolesc Psychiatr 18(1):26-32. doi:10.1007/s00787-008-0698-4

Larriviere D, Williams MA, Rizzo M, Bonnie RJ (2009) Responding to requests from adult patients for neuroenhancements: guidance of the Ethics, law and humanities committee. Neurology 73(17):1406-1412. doi:10.1212/WNL.0b013e3181beecfe

Leucht S, Heres S, Davis JM (2011) Überlegungen zur Wirksamkeit von Psychopharmaka. Nervenarzt 82:1425-1430. doi:10.1007/ s00115-011-3349-9

Mahoney MJ, Arnkoff DB (1978) Cognitive and self-control therapies. In: Garfield SL, Bergin AE (eds) Handbook of psychotherapy and behavior change: an empirical analysis. Wiley, New York, pp 689-722

Mehta MA, Krause J (2011) Emission tomography in ADHD. In: Buitelaar JK, Kan CC, Asherson P (eds) ADHD in adults. Characterization, diagnosis and treatment. Cambridge University Press, Cambridge, pp 75-90

Mill J, Sagvolden T, Asherson P (2005) Sequence analysis of Drd2, Drd4, and Dat1 in SHR and WKY rat strains. Behav Brain Funct 1:24. doi:1744-9081-1-24

Murphy K (2005) Psychosocial treatments for ADHD in teens and adults: a practice-friendly review. J Clin Psychol 61:607-619. doi:10.1002/jclp. 20123

Nakao T, Radua J, Rubia K, Mataix-Cols D (2011) Gray matter volume abnormalities in ADHD: voxel-based meta-analysis exploring the effects of age and stimulant medication. Am J Psychiatr 168(11): 1154-1163. doi:10.1176/appi.ajp.2011.11020281

O'Keeffe SM, Thome J, Coogan AN (2011) The noradrenaline reuptake inhibitor atomoxetine phase-shifts the circadian clock in mice. Neuroscience

Oosterloo M, Lammers GJ, Overeem S, de Nord I, Kooij JJ (2006) Possible confusion between primary hypersomnia and adult attentions-deficit/hyperactivity disorder. Psychiatr Res 143: 293-297. doi:10.1016/j.psychres.2006.02.009

Philipsen A, Graf E, Tebartz van Elst L, Jans T, Warnke A, Hesslinger B, Ebert D, Gerlach M, Matthies S, Colla M, Jacob C, Sobanski E, Alm B, Rösler M, Ihorst G, Gross-Lesch S, Gentschow L, Kis B, Huss M, Lieb K, Schlander M, Berger M (2010) Evaluation of the efficacy and effectiveness of a structured disorder tailored psychotherapy in ADHD in adults: study protocol of a randomized controlled multicentre trial. ADHD Atten Defic Hyperact Disord 2:203-212. doi:10.1007/ s12402-010-0046-7

Proal E, Reiss PT, Klein RG, Mannuzza S, Gotimer K, RamosOlazagasti MA, Lerch JP, He Y, Zijdenbos A, Kelly C, Milham MP, Castellanos FX (2011) Brain gray matter deficits at 33-year follow-up in adults with attention-deficit/hyperactivity disorder established in childhood. Arch Gen Psychiatr 68(11):1122-1134. doi:68/11/1122

Ramsay JR, Rostain AL (2007) Psychosocial treatments for attentiondeficit/hyperactivity disorder in adults: Current evidence and 
future directions. Prof Psychol Res Pract 38:338-346. doi: 10.1037/0735-7028.38.4.338

Retz W, Retz-Junginger P, Hengesch G, Schneider M, Thome J, Pajonk FG, Salahi-Disfan A, Rees O, Wender PH, Rosler M (2004) Psychometric and psychopathological characterization of young male prison inmates with and without attention deficit/ hyperactivity disorder. Eur Arch Psychiatr Clin Neurosci 254(4):201-208. doi:10.1007/s00406-004-0470-9

Retz W, Freitag CM, Retz-Junginger P, Wenzler D, Schneider M, Kissling C, Thome J, Rosler M (2008) A functional serotonin transporter promoter gene polymorphism increases ADHD symptoms in delinquents: interaction with adverse childhood environment. Psychiatr Res 158(2):123-131. doi:10.1016/j.psychres. 2007.05.004

Retz W, Retz-Junginger P, Thome J, Rosler M (2011) Pharmacological treatment of adult ADHD in Europe. World J Biol Psychiatr 12(Suppl 1):89-94. doi:10.3109/15622975.2011.603229

Rodriguez PD, Simon-Dack SL (2011) Factor analysis of five adult ADHD self-report measures: are they all the same? J Atten Disord. doi: 1087054711423627

Rogers ES, Spalding SL, Eckard AA, Wallace LS (2009) Are patientadministered attention deficit hyperactivity disorder scales suitable for adults? J Atten Disord 13(2):168-174. doi:10870 54708323017

Romanos M, Buske-Kirschbaum A, Fölster-Holst R, Gerlach M, Weidinger S, Schmitt J (2011) Itches and scratches-is there a link between eczema, ADHD, sleep disruption and food hypersensitivity? Allergy 66(11):1407-1409. doi:10.1111/ j.1398-9995.2011.02705.x

Rosler M, Retz W, Thome J, Schneider M, Stieglitz RD, Falkai P (2006) Psychopathological rating scales for diagnostic use in adults with attention-deficit/hyperactivity disorder (ADHD). Eur Arch Psychiatr Clin Neurosci 256(Suppl 1):i3-i11. doi: 10.1007/s00406-006-1001-7

Rosler M, Retz W, Stieglitz RD (2010) Psychopathological rating scales as efficacy parameters in adult ADHD treatment investigations - benchmarking instruments for international multicentre trials. Pharmacopsychiatry 43(3):92-98. doi:10.1055/s-00291242819

Rostain AL, Ramsay JR (2006) A combined treatment approach for adults with ADHD - Results of an open study of 43 patients. J Atten Disord 10:150-159. doi:10.1177/1087054706288110

Russell VA (2011) Overview of animal models of attention deficit hyperactivity disorder (ADHD). Curr Protoc Neurosci Chapter 9:Unit9 35. doi:10.1002/0471142301.ns0935s54

Safren SA (2006) Cognitive-behavioral approaches to ADHD treatment in adulthood. J Clin Psychiatr 67(Suppl 8):46-50

Safren SA, Otto MW, Sprich S, Winett CL, Wilens TE, Biederman J (2005) Cognitive-behavioral therapy for ADHD in medicationtreated adults with continued symptoms. Behav Res Ther 43:831-842. doi:10.1016/j.brat.2004.07.001

Safren SA, Sprich S, Mimiaga MJ, Surman C, Knouse L, Groves M, Otto MW (2010) Cognitive behavioral therapy vs relaxation with educational support for medication-treated adults with ADHD and persistent symptoms: a randomized controlled trial. JAMA 304:875-880. doi:10.1001/jama.2010.1192

Sagvolden T (2000) Behavioral validation of the spontaneously hypertensive rat (SHR) as an animal model of attention-deficit/ hyperactivity disorder (AD/HD). Neurosci Biobehav Rev 24(1):31-39. doi:S0149-7634(99)00058-5

Sagvolden T (2011) Impulsiveness, overactivity, and poorer sustained attention improve by chronic treatment with low doses of 1-amphetamine in an animal model of attention-deficit/hyperactivity disorder (ADHD). Behav Brain Funct 7:6. doi:17449081-7-6
Sagvolden T, Johansen EB (2011) Rat models of ADHD. Curr Top Behav Neurosci. doi:10.1007/7854_2011_126

Sagvolden T, Russell VA, Aase H, Johansen EB, Farshbaf M (2005) Rodent models of attention-deficit/hyperactivity disorder. Biol Psychiatr 57(11):1239-1247

Schneider M, Retz W, Coogan A, Thome J, Rosler M (2006) Anatomical and functional brain imaging in adult attentiondeficit/hyperactivity disorder (ADHD)—a neurological view. Eur Arch Psychiatr Clin Neurosci 256(Suppl 1):i32-i41. doi: 10.1007/s00406-006-1005-3

Schredl M, Alm B, Sobanski E (2007) Sleep quality in adult patients with attention deficit hyperactivity disorder (ADHD). Eur Arch Psychiatr Clin Neurosci 257(3):164-168. doi:10.1007/s00406006-0703-1

Seixas M, Weiss M, Muller U (2011) Systematic review of national and international guidelines on attention-deficit hyperactivity disorder. J Psychopharmacol. doi:0269881111412095

Shaw P, Sharp WS, Morrison M, Eckstrand K, Greenstein DK, Clasen LS, Evans AC, Rapoport JL (2009) Psychostimulant treatment and the developing cortex in attention deficit hyperactivity disorder. Am J Psychiatr 166(1):58-63. doi:10.1176/appi.ajp. 2008.08050781

Sheehan DV, Lecrubier Y, Sheehan KH, Amorim P, Janavs J, Weiller E, Hergueta T, Baker R, Dunbar GC (1998) The miniinternational neuropsychiatric interview (M.I.N.I.): the development and validation of a structured diagnostic psychiatric interview for DSM-IV and ICD-10. J Clin Psychiatr 59(Suppl 20): 22-33

Siesser WB, Zhao J, Miller LR, Cheng SY, McDonald MP (2006) Transgenic mice expressing a human mutant betal thyroid receptor are hyperactive, impulsive, and inattentive. Genes Brain Behav 5(3):282-297. doi:10.1111/j.1601-183X.2005.00161.x

Simchon Y, Weizman A, Rehavi M (2010) The effect of chronic methylphenidate administration on presynaptic dopaminergic parameters in a rat model for ADHD. Eur Neuropsychopharmacol 20(10):714-720

Smith AK, Mick E, Faraone SV (2009) Advances in genetic studies of attention-deficit/hyperactivity disorder. Curr Psychiatr Rep 11(2):143-148. doi:10.1007/s11920-009-0022-0

Solanto MV (2011) Cognitive-behavioral therapy for adult ADHD: targeting executive dysfunction. Guilford Press, New York

Solanto MV, Marks DJ, Mitchell KJ, Wasserstein J, Kofman MD (2008) Development of a new psychosocial treatment for adult ADHD. J Atten Disord 11:728-736

Sontag TA, Tucha O, Walitza S, Lange KW (2010) Animal models of attention deficit/hyperactivity disorder (ADHD): a critical review. Atten Defic Hyperact Disord 2(1):1-20. doi:10.1007/ s12402-010-0019-x

Taylor E et al (2008) National institute for health and clinical excellence (NICE) attention deficit hyperactivity disorderdiagnosis and management of ADHD in children, young people and adults. NICE Clinical Guidelines 72

Taylor E (2011) Antecedents of ADHD: a historical account of diagnostic concepts. ADHD Atten Def Hyp Disord 3(2):69-75. doi: 10.1007/s12402-010-0051-x

Taylor A, Deb S, Unwin G (2011) Scales for the identification of adults with attention deficit hyperactivity disorder (ADHD): a systematic review. Res Dev Disabil 32(3):924-938. doi: 10.1016/j.ridd.2010.12.036

Thome J, Jacobs KA (2004) Attention deficit hyperactivity disorder (ADHD) in a 19th century children's book. Eur Psychiatr 19(5):303-306. doi:10.1016/j.eurpsy.2004.05.004.S092493380 4001063

Valenzuela M, Bartrés-Faz D, Beg F, Fornito A, Merlo-Pich E, Müller U, Öngür D, Toga AW, Yücel M (2011) Neuroimaging as 
endpoints in clinical trials: are we there yet? Perspectives from the first Provence workshop. Mol Psychiatr 16:1064-1066

van den Bergh FS, Bloemarts E, Chan JS, Groenink L, Olivier B, Oosting RS (2006) Spontaneously hypertensive rats do not predict symptoms of attention-deficit hyperactivity disorder. Pharmacol Biochem Behav 83(3):380-390

Van der Heijden KB, Smits MG, Van Someren EJ, Gunning WB (2005) Idiopathic chronic sleep onset insomnia in attentiondeficit/hyperactivity disorder: a circadian rhythm sleep disorder. Chronobiol Int 22(3):559-570. doi:10.1081/CBI-200062410

Van Veen MM, Kooij JJ, Boonstra AM, Gordijn MC, Van Someren EJ (2010) Delayed circadian rhythm in adults with attentiondeficit/hyperactivity disorder and chronic sleep-onset insomnia. Biol Psychiatr 67(11):1091-1096

Van Voorhees EE, Hardy KK, Kollins SH (2011) Reliability and validity of self- and other-ratings of symptoms of ADHD in adults. J Atten Disord 15(3):224-234. doi:1087054709356163

Veerhuis R, Nielsen HM, Tenner AJ (2011) Complement in the brain Mol Immunol 48(14):1592-1603

Virta M, Vedenpää A, Grönroos N, Chydenius E, Partinen M, Vataja R, Kaski M, Iivanainen M (2008) Adults with ADHD benefit from cognitive-behaviorally oriented group rehabilitation-a study of 29 participants. J Atten Disord 12:218-226. doi: $10.1177 / 1087054707311657$

Volkow ND, Wang GJ, Newcorn J, Telang F, Solanto MV, Fowler JS, Logan J, Ma Y, Schulz K, Pradhan K, Wong C, Swanson JM (2007) Depressed dopamine activity in caudate and preliminary evidence of limbic involvement in adults with attention-deficit/ hyperactivity disorder. Arch Gen Psychiatr 64:932-940. doi: 10.1001/archpsyc.64.8.932

Volkow ND, Wang GJ, Kollins SH, Wigal TL, Newcorn JH, Telang F, Fowler JS, Zhu W, Logan J, Ma Y, Pradhan K, Wong C, Swanson JM (2009) Evaluating dopamine reward pathway in ADHD: clinical implications. JAMA 302(10):1084-1091. doi: 302/10/1084

Volkow ND, Wang GJ, Newcorn JH, Kollins SH, Wigal TL, Telang F, Fowler JS, Goldstein RZ, Klein N, Logan J, Wong C,
Swanson JM (2011) Motivation deficit in ADHD is associated with dysfunction of the dopamine reward pathway. Mol Psychiatr 16(11):1147-1154

Volkow ND, Wang GJ, Tomasi D, Kollins SH, Wigal TL, Newcorn JH, Telang FW, Fowler JS, Logan J, Wong CT, Swanson JM (2012) Methylphenidate-elicited dopamine increases in ventral striatum are associated with long-term symptom improvement in adults with attention deficit hyperactivity disorder. J Neurosci 32:841-849. doi:10.1523/JNEUROSCI.4461-11.2012

Weiss M, Vincent A (2011) CADDRA Canadian and resource alliance Canadian ADHD practice guidelines (CAP-Guidelines), $3 r d$ edn

Weiss MD, Weiss JR (2004) A guide to the treatment of adults with ADHD. J Clin Psychiatr 65(Suppl. 3):23-37

Won H, Mah W, Kim E, Kim JW, Hahm EK, Kim MH, Cho S, Kim J, Jang H, Cho SC, Kim BN, Shin MS, Seo J, Jeong J, Choi SY, Kim D, Kang C (2011) GIT1 is associated with ADHD in humans and ADHD-like behaviors in mice. Nat Med 17(5):566-572

Wood DR, Reimherr FW, Wender PH, Johnson GE (1976) Diagnosis and treatment of minimal brain dysfunction in adults: a preliminary report. Arch Gen Psychiatr 33(12):1453-1460

Wulff K, Gatti S, Wettstein JG, Foster RG (2010) Sleep and circadian rhythm disruption in psychiatric and neurodegenerative disease. Nat Rev Neurosci 11(8):589-599

Xu X, Breen G, Chen CK, Huang YS, Wu YY, Asherson P (2010) Association study between a polymorphism at the $3^{\prime}$-untranslated region of CLOCK gene and attention deficit hyperactivity disorder. Behav Brain Funct 6:48

Yoon SY, Jain U, Shapiro C (2011) Sleep in attention-deficit/ hyperactivity disorder in children and adults: Past, present, and future. Sleep Med Rev (in press)

Young S, Gudjonsson GH (2005) Neuropsychological correlates of the YAQ-S and YAQ-I self- and informant-reported ADHD symptomatology, emotional and social problems and delinquent behaviour. Br J Clin Psychol 44(Pt 1):47-57. doi:10.1348/01446 6504X197769 